\title{
A Study on Constructing Internal Teaching Quality Monitoring and Security System in Colleges and Universities
}

\author{
Shu Liu ${ }^{1, a^{*}}$, Qinghong Qu ${ }^{2, b}$ \\ ${ }^{1}$ College of Mechanical Engineering, Baicheng Normal University, Baicheng,137000,China \\ ${ }^{2}$ Media College, Baicheng Normal University, Baicheng, 137000,China \\ aemail:dimnet@163.com , bemail:quqinghong@163.com, "corresponding author
}

Key words: Colleges and Universities, Teaching quality, Monitoring and Security System

\begin{abstract}
The teaching quality is not only one of the most important standards to evaluate the levels of colleges and universities, but also one of the most significant factors, by which the quality of these universities is measured. In present days, teaching quality plays the most vital roles in deciding the quality and standards of universities, because there are fierce competitions among universities. Therefore, it is the most important work for the universities to improve their teaching quality continuously. In order to improve the internal teaching quality of universities, researches were focused on the internal teaching quality monitoring and security systems in this paper.
\end{abstract}

\section{Introduction}

Chinese higher education is facing many new statuses, such as the development of knowledge economy, the competition of teaching resources, the expansion of the scale of China's higher education and the changing from elite education to popular education. All these brought not only new opportunities but also challenges to the teaching management in institutions of higher learning.

Under the background of new era, the institutions of higher learning is becoming more competitive. In order to get further development and progress, colleges and universities must improve their teaching quality to get more social approval so that it can attract more students and prompt the further development and construction.

So, it has become an essential problem that how to effectively monitor the teaching quality and prompt its further development for many institutions of higher learning[1][2]. Many questions about constructing teaching quality monitoring and security system are discussed in this paper in order to provide beneficial reference to relevant persons.

\section{Significance of constructing teaching quality monitoring and security system in institution of higher teaching}

Constructing teaching quality monitoring and security system is the essential means to cope with the new situation. With the development of knowledge economy, our country's higher education scale expands unceasingly. Under the background of new era, the challenges and setbacks which colleges and universities have to face are further increasing.

On one hand, with the enrollment expansion of institutions of higher learning, the quality of the students is affected. Under the national policy, the number of students in higher school enroll is constantly expanding. It reduced the quality of students from another perspective. So the quality of teaching is affected from the perspective of students. It becomes the new challenge for improving the quality of teaching in the institution of higher learning ${ }^{[1]}$.

On the other hand, colleges and universities are facing the increasingly fierce competition. Specifically, with the construction of institutions of higher learning, all kinds of vocational colleges are undergoing further development. It greatly increases the competitive strength of institutions of higher learning. In order to achieve the further development, institutions of higher learning need to 
constantly improve their teaching quality. It can attract more outstanding students, and ultimately maintain our reputation at the same time.

It can draw a conclusion that constructing internal teaching quality monitoring and security system of institutions of higher learning can effectively guarantee the teaching quality and make its further development. So the development of the work is an essential way for colleges and universities to establish a foothold under the new background. It is also the inevitable trend of education development in our country.

Constructing teaching quality monitoring and security system is the requirement of cultivating high quality talents. With the continuous development of social economy, the requirements of the talents are constantly increasing. This is also the root cause of continual expanding scale of higher education in China.

Specifically, institutions of higher learning must give full play to their function, through continuously improve their teaching quality and teaching management quality, and cultivate the talents of higher quality, to meet the demand of the market, provide help for the further development of our social economy.

By constructing internal teaching quality monitoring and security system, institutions of higher learning can carry out the effective supervision to the teaching idea, teaching method and teaching pattern, and encourage teachers to implement the new teaching concept, and constantly improve the quality of classroom teaching.

At the same time, institutions of higher learning can also carry out effective constraints on student's learning attitude, learning motivation, etc. It can motivate students to study hard to improve the quality and efficiency, and help students to develop and grow, eventually help them to become high quality talents.

\section{The current status of quality monitoring and security systems in higher education}

The feedback of education quality monitoring and teaching quality security systems is reflected according to the tasks of class observation, verification in undergraduate programs and term inspection by the Office of Academic Affairs, by which many problems still exist although great achievements have been made[3].

The responsibilities and monitoring mechanisms should be clearer. The quality monitoring and security system of higher education, which play key roles in the managements of all the tasks, involve all kinds of aspects within the universities. The teaching quality monitoring system of colleges and universities should be strictly regulated(Figure1), but teaching quality monitoring is inefficient at present situation, because there are neither independent departments nor privileges (if any) of them to supervise educational quality in universities, which are the causes of the lacks of ability to monitor teaching quality effectively by universities.

The educational quality is lack of supervising and the teaching quality security systems is lack of the implementation capacity. Rules and regulations have been formulated to supervising the educational quality, but they don't work for the sake of friendship among colleagues. Teachers who violate the rules or regulations, usually will not be punished, because they can be shielded by the supervisors or their leaders, which means that these rules or regulations exist in name only.

The evaluation systems on educational quality are unreasonable. The evaluation systems usually put particular emphasis on the class teaching, but ignore the practice teaching. Other problems of evaluation systems on educational quality in the universities are the lacks of supervising teaching steps, teaching links as well as the use of textbooks. 
Feedback is absent to appraise teaching quality in evaluation systems. Attentions have been paid greatly to the practices and evaluation of the rules of quality security systems, but not to the feedback and the continuing work of teaching quality. Feedback, especially that among departments, can not be deal well during the proceeding of evaluating educational quality, let alone constructing the feedback chains, and the feedback from the teaching procedures usually ends up.

The obsolete knowledge structures of administrative staff can not catch up with the practices of education quality monitoring in present days. On one side, the number of administrative staff in universities, who have educating backgrounds in sciences of educational management, is much low, and they fulfill the teaching managements by means of gathering experiences from daily work; on the other side, it is difficult for them to get the chances of in-service training to improve their standards of teaching managements, which makes them to act blindly in monitoring and managing the educational quality in universities.

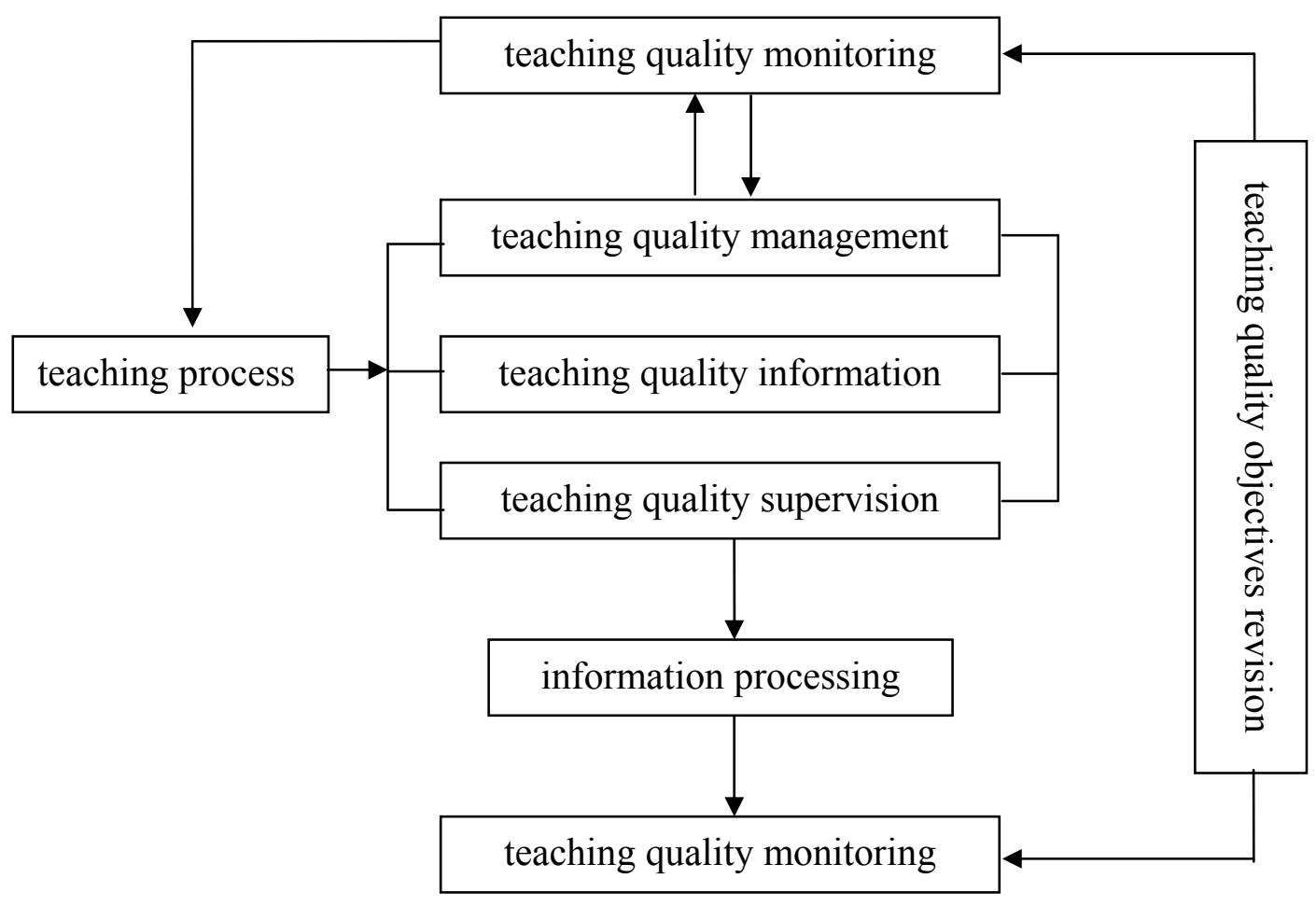

Figure1.Operating procedure of teaching quality monitoring

\section{Strategies of constructing the internal educational quality monitoring and security systems in universities}

In order to construct the internal educational quality monitoring and security systems in universities, effective evaluation methods should be optimized and improved[4].

For the sake of supervising and ensuring the educational quality effectively and totally, the methods should be aimed at two lines of evaluations, one for teachers and the other for students. For one thing, periodical teaching evaluations should be conducted to monitoring the teaching quality of teachers, from the points of views of the teaching philosophies, the teaching methods as well as the 
teaching contents, meanwhile, practice teaching should be one of the main targets to assess the teaching quality of teachers in universities.

In a sense, teaching quality standards of teachers cannot be reflected across-the-aboard just by means of theoretical evaluations, but the practice teaching can be used well to reflect the real standards of them through visiting classes periodically by other teachers and the teaching quality can be assessed according to the studying effects of the students in practice.

By this means, the impetuses and stresses of the teachers can be developed to improve their teaching quality standards according to the reform and renewal in their teaching philosophies and using flexible teaching methods as well.

For the other, learning quality of students should not just be confined in evaluating the daily learning situation and terminal examination, which cannot reflect well the real learning effects and standards of the students.

The feedback systems to reflect the students' learning situation, effects and standards should be built by universities. Specific and professional departments in universities should be founded to supervise the learning situation in class randomly, by which the facticity and availability of the feedback from the students can be improved greatly and the possibilities of false feedback from the students can be decreased as well. Students can be selected randomly to have tests in offices of the departments in universities, by which the real learning situation and effects of the students can be reflected well.

The teaching quality can be increased effectively through the two kinds of evaluation methods, which are helpful for the students to improve their studying attitudes and enthusiasms with certain stresses.

Initiatives and enthusiasms of the teachers and students should be considered well to construct the internal teaching quality monitoring and security systems in universities.

The behaviors and work efficiency of the teachers and students have been restrict and controlled already by the powerful evaluation methods, but depressions may come from the students and teachers just depending on these uncompromising rules.

Based on these powerful rules and regulations, effective encouraging methods should be built in universities, by which the enthusiasms of the teachers and students can be increased greatly.

For the teachers, encouraging policies and methods with oriented effects should be constructed to increase the teachers' enthusiasms and improve the teaching quality according to the teacher's work, such as, the polices of "lecture competitions among the young teachers", "award methods for excellent teaching achievement" and "the identifying methods for honorable mention of teaching", etc[5]. For the students, their studying enthusiasms can be increased by the policies of "outstanding student awards" and "bonuses for outstanding students achievements", which are constructed based on disinterested evaluation methods in universities.

All in all, it is necessary to increase and arouse the enthusiasms of the teachers and students to improve the teaching quality through effective encouraging methods, by which the subjective initiatives of the teachers and students can be exerted and they will work hard in universities.

\section{Summary}

It is the inexorable trend for the universities to build their internal educational quality monitoring and security systems, which are the available methods for the development and construction of the universities as well. The significance of constructing the internal educational quality monitoring and 
security systems in universities is that the construction work of universities can be developed and promoted efficiently by continuing reforms and innovations in improving teaching quality.

\section{References}

[1] Zengfu Ding, Xinyong Ge. Construct the monitoring systems to improve the teaching quality in universities[J]. Higher Agricultural Education, 2004 (3)47-49.

[2] Nianhai Qiu. Research on the construction of internal educational quality monitoring and security systems in universities[J]. Economic research guide, 2011 (13) 253-254.

[3] Guoqing Gui, Qingzhong Chang, Jiangen Huang. The issues of the teaching quality control system of newly-built local undergraduate college \& our countermeasures[J], China higher education research, 2007 (7).

[4] Caimei $\mathrm{Hu}$, Xuhong Tan, Yinghui Wu. Construction and Implementation of Supervision System of Whole Teaching Quality in Universities[J], Continue education research, 2008 (2).

[5] Jiacheng Zheng, Quanxu He. Optimization of Teaching Quality Internal Management Mechanism in Higher Education[J],Exploring education development, 2007 (29). 